\title{
Stability of Upper Face Height-Total Face Height Ratio with Increasing Age
}

\author{
CARLOS E. NASJLETI and CHARLES J. KOWALSKI \\ Veterans Administration Hospital and Dental Research Institute, University of \\ Michigan, Ann Arbor, Michigan 48104, USA
}

A number of investigators, while recognizing that vertical facial dimensions continue to increase throughout adulthood, have commented on the relative constancy of vertical facial proportions during growth. Broadbent (Angle Orthod 7: 209, 1937) claimed that a proportional increase in the size of the segments of the face occurs after deciduous dentition is completed. Brodie $(\mathrm{Am} \mathrm{J}$ Orthod 26: 741, 1940; Am J Anat 68: 209, 1941) stated that upper face height always constitutes $43 \%$ of the total face height, whether one studies the newborn, a child, or an adult. Herzberg and Holic ( $A m$ J Orthod 29: 90, 1943), in a study of 326 adult skulls of differing racial origins, found that upper facial height comprised $43.5 \%$ of the total face height; Särnas (Acta Odontol Scand 15: 218,1957 ), finding similar results in a study of ancient skulls, concluded that this ratio was unaffected by age and has not changed significantly through time or with race from ancient to modern man. However, some studies have produced conflicting results. Thompson and Kendrick (Anat Rec 150: 209, 1964), for example, found that lower face height increased more than upper face height through the third and fourth decades of life, but cited several earlier studies claiming that increases in upper face height were most responsible for increases in total face height, and although upper face height continues to increase through the mid-fifties, total face height decreases after age 35 .

The purpose of the present report is to present some new data having a bearing on the question of whether or not the upper face

Received for publication January 20, 1975.

Accepted for publication May 8, 1975.

Reprint requests to Dr. Kowalski, 3211 Dental School, University of Michigan, Ann Arbor, Mich. height-total face height ratio remains constant with increasing age. The study sample was comprised of a total of 510 white male individuals between 20 and 86 years of age. Each of these individuals was seen for care at the Veterans Administration Hospital in Ann Arbor and each had a sufficiently natural occlusion, with anterior and posterior centric stops, so that total face height in centric occlusion could be reliably determined. Total face height was measured as the distance from nasion to menton and upper face height was measured, along this line, from nasion to the line connecting the anterior and posterior nasal spines (ANS to PNS).

The data are summarized in the table where the sample sizes and the mean values of upper facial height, total facial height, and upper facial height-total facial height ratio are given for each of the age groups. The column headed standard deviation contains the standard deviations of the upper facial height-total facial height ratios within each of the age groups considered. It is seen that although slight, but definite, increases in facial height occur throughout the age interval considered, the upper facial height-total facial height ratio remains remarkably constant with increasing age, being of the order of $43.5 \%$ throughout adulthood. Although individual variations about this value do occur (Scotr, Trans Europ Orthodont Soc p 83, 1955) and the interpretation of these results in terms of growth rates (BAER, Am I Phys Anthropol 14: 557, 1956) and clinical significance (MOoRe, $A m J$ Orthod $45: 399,1959)$ requires considerable care, the results of this study do support the contention that the upper face height-total face height ratio remains relatively constant throughout adulthood, at least among individuals who have relatively intact dentitions.

TABLE

Average Values of Vertical facial Dimensions for Several Age Groups

\begin{tabular}{lccccc}
\hline $\begin{array}{c}\text { Age } \\
\text { Interval }\end{array}$ & $\begin{array}{c}\text { Sample } \\
\text { Size }\end{array}$ & $\begin{array}{c}\text { Upper Facial } \\
\text { Height (mm) }\end{array}$ & $\begin{array}{c}\text { Total Facial } \\
\text { Height (mm) }\end{array}$ & $\begin{array}{c}\text { Upper-Total } \\
\text { Facial Height } \\
\text { Ratio (\%) }\end{array}$ & $S D$ \\
\hline $20-29$ & 130 & 58.97 & 134.72 & 43.83 & 2.2 \\
$30-39$ & 88 & 59.29 & 137.16 & 43.29 & 2.4 \\
$40-49$ & 125 & 59.70 & 137.02 & 43.62 & 2.1 \\
$50-59$ & 122 & 59.39 & 137.50 & 43.23 & 2.1 \\
$\cong 60$ & 45 & 60.91 & 139.66 & 43.65 & 2.2 \\
\hline
\end{tabular}

